\title{
Aerobic Capacity and Ventilatory Response During Incremental Exercise in Elite High School Cyclist
}

\author{
Dae Taek Lee* and Yoon Jung Bae
}

Kim Chang Kew Exercise Physiology Laboratory, Kookmin University, Seoul 136-702, Korea

Received February 1, 2010 /Accepted March 22, 2010

\begin{abstract}
This study was designed to examine the aerobic capacity and ventilatory response during an incremental exercise in elite high school cyclists. Twelve boys $(17 \pm 1 \mathrm{yr}, 175 \pm 5 \mathrm{~cm}, 70 \pm 9 \mathrm{~kg})$ participated in anthropometric measurements, incremental exercise testing, and pulmonary function tests. During incremental exercise testing using a cycle ergometer, their maximal oxygen uptake $\left(\mathrm{VO}_{2} \mathrm{max}\right)$, maximal power output, ventilation, ventilatory equivalents for oxygen $\left(\mathrm{V}_{\mathrm{E}} / \mathrm{VO}_{2}\right)$ and carbon dioxide $\left(\mathrm{V}_{\mathrm{E}} / \mathrm{VCO}_{2}\right)$, respiratory rate, and tidal volume were measured. Time variables such as inspiratory time (Ti), expiratory time (Te), breathing time $(\mathrm{Tb})$, and inspiratory duty cycle $(\mathrm{Ti} / \mathrm{Tb})$, as well as inspiratory flow rate $\left(\mathrm{V}_{\mathrm{T}} / \mathrm{Ti}\right)$ were assessed. Pulmonary function of vital capacity $(\mathrm{FVC})$, forced expiratory volume in one second $\left(\mathrm{FEV}_{1}\right), \mathrm{FEV}_{1} / \mathrm{FVC}$, and peak expiratory flow were evaluated. Their $\mathrm{VO}_{2} \mathrm{max}$, maximal heart rate, and Wmax were $57.5 \pm 3.9 \mathrm{ml} \cdot \mathrm{kg}^{-1} \cdot \mathrm{min}^{-1}, 194.1 \pm 8.6$ beat $\cdot \mathrm{min}^{-1}$, and $452 \mathrm{~W}$, respectively. $\mathrm{VO}_{2} \max$ was not related to any anthropometric parameters. Most ventilatory variables progressively increased with exercise intensity. As intensity increased, $\mathrm{Ti}, \mathrm{Tb}, \mathrm{Tb}$ decreased while $\mathrm{Ti} / \mathrm{Tb}$ was maintained. Below an intensity of $250 \mathrm{~W}$, height, weight, body mass index, and body surface were highly correlated with $\mathrm{V}_{\mathrm{T}} / \mathrm{Ti}$ and $\mathrm{Ti} / \mathrm{Tb}(\mathrm{p}<0.05)$. Collectively, $\mathrm{VO}_{2} \mathrm{max}$ appeared to be lower than adult cyclists, suggesting a different pattern of ventilatory control as age advances. Morphological characteristics were not related to $\mathrm{VO}_{2}$ max in the population. Time variables of ventilatory response seemed to be related only at an exercise intensity level of less than $250 \mathrm{~W}$. $\mathrm{V}_{\mathrm{T}} / \mathrm{Ti}$ may be related to exercise endurance capacity, but $\mathrm{Ti} / \mathrm{Tb}$ was similar to adult cyclists.
\end{abstract}

Key words : Maximal oxygen uptake, ventilation, elite cyclist, time variables, breathing control

\section{서 론}

유산소성 대사능력은 선수의 체력과 훈련 효과를 살펴보는 중요한 생리학적 변인 중의 하나이며, 대부분의 경우 최대산 소섭취량(maximal oxygen uptake: $\mathrm{VO}_{2} \mathrm{max}$ )으로 측정되는 데, 이는 선수의 지구성 능력을 결정하는 요인으로 평가된다 [4,7]. 지구성을 요구하는 운동종목에서 잘 훈련된 선수의 $\mathrm{VO}_{2} \mathrm{max}$ 는 상대적으로 높으며 우수한 경기력을 유지하는 기 본 조건으로 여겨진다[13]. 그래서 운동 선수의 훈련과 경기력 을 최적화하기 위해 유산소성 대사 요구와 반응을 평가하는 것이 중요하다.

국제수준의 사이클 선수의 특징 중 하나는 이들의 최대능력 이 상당 수준에 이른다는 것이다. 그리고 이들 선수를 대상으 로 $\mathrm{VO}_{2} \mathrm{max}$ 와 최대파워에 대한 연구가 많이 진행되어왔다[25, 27]. 엘리트 사이클 선수들은 약 $70-80 \mathrm{ml} \cdot \mathrm{kg}^{-1} \cdot \mathrm{min}^{-1}$ 의 $\mathrm{VO}_{2} \mathrm{max}$ 를 보이며, 검사 방법에 따라 차이가 존재하지만 약 400-500 $\mathrm{W}$ 의 최대파워능력을 가진 것으로 보고되고 있다[19]. 이러한 결과는 훈련에 의한 종목 특이성 체력 변화로 간주된다.

*Corresponding author

Tel : +82-2-910-4781, Fax : +82-2-901-4780

E-mail : dtlee@kookmin.ac.kr
사이클 선수들에 대한 연구가 상대적으로 많이 진행되었음 에도 국내에서는 사이클 선수와 관련하여 아직 체계적으로 진행된 연구들이 소수에 지나지 않는다[14,15,28]. 특히 중,고 교 어린 선수에 대한 유산소성 대사 능력에 대한 자료는 그리 많지 않다[14,15,17]. 어린 선수들에 대한 평가는 측정항목에 포함된 생리적 변인들의 절대적인 수치를 얻는다는 것에 중요 성이 있기도 하겠지만, 이들이 과연 성인 선수들에 비해 어떠 한 다른 대사적 반응을 보이는가를 연구하는데도 중요한 이유 가 있을 것이다. 그러나 현재까지 어린 사이클 선수들의 유산 소 능력에 대한 구체적 평가는 진행되지 않았다. 이러한 평가 는 어린 선수들에게 있어 고된 훈련이 호흡반응을 어떻게 변 화시키는지를 이해하는데 도움을 주게 된다.

최대유산소능력에서와 같이 점진부하운동 평가에서 호흡 반응에 대한 연구는 많이 진행되었다[10, 20]. 몇몇 연구들은 낮은 운동강도에서 환기량이 증가하는 이유가 일회호흡량과 호흡률의 동반 증가에 의한 것이라면, 강한 운동강도에서 환 기량의 증가는 일회호흡량이 유지되는 가운데 호흡률의 증가 에 의존된다고 설명하고 있다[10,22]. 다른 연구들에서는 신체 훈련 이후 최대하운동에서 증가하는 호흡량이 일회호흡량의 증가와 상대적으로 낮은 호흡률 반응을 보였다고 보고하고 있다[9,31]. 또한 이러한 호흡반응은 연구 대상자의 체력수준 
에 따라 달리 나타날 수 있다는 가능성도 제기되고 있으며[18], 반대로 체력과는 상관이 없다는 보고도 존재한다 $[9,21,31]$. 그 러나 잘 훈련된 사이클 선수들에 대한 호흡반응을 평가한 연 구들은 존재하지만[8,30] 사이클과 연관되어, 특히 국내의 어 린 선수들의 점진부하운동 평가 중 나타나는 호흡반응에 대한 연구는 없다.

어린 엘리트 사이클 선수들에게 점진적 운동부하를 제공하 여 자발적 피로에 도달하는 경우에 이들의 유산소 대사반응과 폐환기 반응을 조사하는 것은 단지 절대적인 수치만을 찾고자 하는 시도는 아니다. 이러한 노력은 잘 훈련된 어린 선수들이 성인의 반응과 같은 유형을 보이는지를 살펴보는데도 중요성 이 존재한다. 이를 통해 어린 선수의 발달과정에서 무엇이 성 인 엘리트 선수와 유사하며 무엇이 다른가를 구별 지을 수 있는 자료를 확보할 수 있기 때문이다. 만약 어린 선수들의 환기반응이 성인의 환기반응과 같은 양상을 보인다면 이는 점진 부하운동 과정에서 호흡반응 연령에 의존하지 않음을 설명하는 것과 마찬가지로 해석될 수 있을 것이다.

따라서 본 연구는 국내 중고등학교 엘리트 사이클 선수들의 유산소능력과 폐기능을 평가하고 점진부하운동 평가 시 호흡 반응이 어떻게 나타나는지를 살펴보는데 목적을 두었다. 그리 고 어린선수들에게서 얻어진 자료를 이미 보고된 성인들의 자료와 비교 분석하였다.

\section{재료 및 방법}

\section{연구 대상자}

선수경력 1-4년의 중학교 및 고등학교 엘리트 사이클 선수 12 명을 연구대상으로 하였다. 이들의 신체적 특징과 유산소성 능력은 Table 1에 나타내었다. 각 선수들의 대략적인 주종목은 단거리 4 명, 중장거리 3 명, 장거리 5 명이었다. 선수들은 본 연 구의 진행과정에 영향을 줄 수 있는 근골격계적 또는 정형학 적 문제를 가지고 있지 않았으며, 최상의 컨디션을 유지하는

Table 1. Young elite cyclists' physical characteristics and aerobic capacity

\begin{tabular}{lcc}
\hline & $\mathrm{M} \pm$ S.D. & $\begin{array}{c}\text { range } \\
(\mathrm{n}=12)\end{array}$ \\
\hline age $(\mathrm{yr})$ & $17.0 \pm 1.3$ & $15-19$ \\
height $(\mathrm{cm})$ & $174.6 \pm 4.8$ & $167-182$ \\
weight $(\mathrm{kg})$ & $70.2 \pm 9.0$ & $60.4-85.1$ \\
body mass index $\left(\mathrm{kg} \cdot \mathrm{m}^{-2}\right)$ & $23.0 \pm 1.9$ & $20.3-26.3$ \\
body fat $(\%)$ & $18.0 \pm 3.9$ & $11.9-22.4$ \\
body surface area $\left(\mathrm{m}^{2}\right)$ & $1.85 \pm 0.13$ & $1.70-2.06$ \\
maximal heart rate $\left(\mathrm{beat} \cdot \mathrm{min}^{-1}\right)$ & $194.1 \pm 8.6$ & $184-206$ \\
maximal oxygen uptake $\left(\mathrm{liter} \cdot \mathrm{min}^{-1}\right)$ & $4.02 \pm 0.45$ & $3.30-4.75$ \\
maximal oxygen uptake $\left(\mathrm{ml} \cdot \mathrm{kg}^{-1} \cdot \mathrm{min}^{-1}\right)$ & $57.5 \pm 3.9$ & $52.4-63.8$ \\
work load at maximal capacity $(\mathrm{W})$ & $391.8 \pm 40.6$ & $302-452$ \\
exercise endurance $(\mathrm{sec})$ & $891 \pm 81$ & $725-1025$ \\
\hline
\end{tabular}

9-10월에 측정이 진행되었다.

\section{인체 계측변인 및 환산}

선수의 신장과 체중이 측정되었으며, 이 수치들을 이용하여 신체질량지수 $\left(\mathrm{kg} / \mathrm{m}^{2}\right.$ 으로 환산 $)$ 와 두보이스의 체표면적[6]이 계산되었다. 체지방률은 생체전기저항측정방식을 이용하여 평가되었다(X-scan Plus II, 자원메디칼, 한국).

\section{유산소성능력 평가 및 환기반응 변인}

유산소성능력은 자전거에르고미터(Excalibur, Lode, 네덜 란드)에서 사이클 선수 측정에 신뢰성이 확보된 점진적 운동 부하 가중방식을 이용하여 최대산소섭취량(maximal oxygen uptake: $\mathrm{VO}_{2} \mathrm{max}$ ) 측정으로 평가되었다. 먼저 에르고미터의 페달을 선수들이 평소에 사용하던 토클립 또는 클립리스 페달 로 바꿔 장착하고 안장 높이와 핸들의 위치를 조절하였다. 에 르고미터 조정이 완료된 후 선수들에게 약 5 분간의 워밍업과 페달링이 가능하도록 하였으며, 이어 무선전자심박측정계 (Polar S810, 핀란드)를 착용하였다. 테크니션에 의해 페이스 마스크가 착용되었으며, 마스크를 통한 호흡이 정상적으로 작 동되는지 확인된 후 실험이 시작되었다. 산소섭취량(oxygen uptake: $\mathrm{VO}_{2}$ )은 마스크와 연결된 호흡가스분석기(Quark PET2 ergo, Cosmed, 이탈리아)를 통해 breath-by-breath 방식 으로 분석되었다. 선수들은 약 $90 \mathrm{rpm}$ 에서 지속적으로 페달링 이 이루어지도록 격려되었다. 평가가 시작되면서 첫 1 분 동안 $20 \mathrm{~W}$ 의 부하가 주어졌으며, 이후 매분마다 $25 \mathrm{~W}$ 가 증가되었 다[20]. 선수들은 가중되는 부하에 더 이상 페달링 속도를 유지 하지 못하거나 더 이상 산소섭취량이 증가하지 않는 단계까지 운동하였다. $\mathrm{VO}_{2} \max$ 는 운동이 종료되기 직전 15 초간의 $\mathrm{VO}_{2}$ 를 평균한 값으로 가정하였다. 선수들이 도달한 최대운동부하 (work load at maximal capacity, $W$ )는 $W_{\text {stage }}+(t / 60) \times 25$ 로 환산되었다. 여기서 $\mathrm{W}_{\text {stage }}$ 는 운동이 끝나는 당시 마지막 운동 강도, $t$ 는 마지막 운동 강도에서 지속한 시간이었다[12]. 실 험은 $25^{\circ} \mathrm{C}, 50 \%$ 상대습도 환경에서 이루어졌다.

호흡가스는 $\mathrm{VO}_{2}\left(\mathrm{liter} \cdot \mathrm{min}^{-1}\right.$ 와 $\mathrm{ml} \cdot \mathrm{kg}^{-1} \cdot \mathrm{min}^{-1}$ 으로 표현)와 이산화탄소 생성량 $\left(\mathrm{CO}_{2}\right.$ production volume: $\left.\mathrm{VCO}_{2}\right)$ 그리고 환기량(expiratory volume: $\mathrm{V}_{\mathrm{E}}$ )을 분석하는데 사용되었으며, 산소호흡당량(ventilatory equivalents for oxygen; $\mathrm{V}_{\mathrm{E}} / \mathrm{VO}_{2}$ ) 과 이산화탄소호흡당량(ventilatory equivalents for carbon dioxide; $\mathrm{V}_{\mathrm{E}} / \mathrm{VCO}_{2}$ )가 환산되었다. 그리고 $\mathrm{VO}_{2}$ 와 $\mathrm{VCO}_{2}$ 를 이용하 여 비단백호흡교환율(respiratory exchange ratio; RER)이 계산 되었다. 또한 분당 호흡률(respiratory ratio: $\mathrm{RR}$, breath $\mathrm{min}^{-1}$ ) 이 측정되고 일회호흡량(tidal volume: $\mathrm{V}_{\mathrm{T}}$, liter)이 환산되었 다. 환기반응의 시간변인으로는 흡기시간(inspiration time: $\mathrm{Ti})$, 호기시간(expiration time: $\mathrm{Te}$ ), 일회호흡시간(breathing time: $\mathrm{Tb}$ )이 측정되었으며, 흡기의무사이클(inspiratory duty cycle; $\mathrm{Ti} / \mathrm{Tb}$ )과 흡기율(inspiratory flow rate: $\mathrm{V}_{\mathrm{T}} / \mathrm{Ti}$ )이 환산 
되었다.

평가 중 심박수(heart rate: $\mathrm{HR}$, beat $\min ^{-1}$ )가 $\mathrm{VO}_{2}$ 와 연동 되어 자동적으로 기록되었으며, 운동시간과 최종 운동강도 및 최대심박수가 기록되었다.

\section{폐기능 평가}

선수들이 폐기능 평가는 유산소성능력 평가와 분리되어 진행 되었다. 선수들은 선 자세에서 가장 많은 공기를 흡입한 후 가장 빠르고 많은 공기를 원통형 마우스피스를 통해 불어내도록 격려되었다(Schiller, SP-1, 스위스). 폐기능은 폐활량(functional vital capacity: FVC, liter), 일초호기량(forced expiratory volume in one second: $\mathrm{FEV}_{1}$, liter), 일초율 $\left(\mathrm{FEV}_{1} / \mathrm{FVC}, \%\right)$,

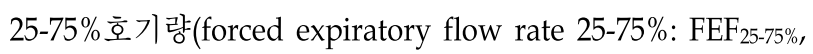
liter), 최대호기량(peak expiratory flow: PEF, liter). 폐기능 평가는 최소한 2번 이상 실시 후에 가장 높은 FVC가 얻어진 결과치를 결과로 채택하였다.

\section{통계처리}

평가에서 얻어진 자료들은 SPSS Window ver. 14.0을 이용 하여 정리, 분석되었으며, 모든 변인은 모든 선수들의 평균과 표준편차로 나타내었다. 유산소성능력 평가는 12 명이, 폐기능 평가는 9명의 선수가 분석되었다. 측정된 변인들의 상관관계 는 Pearson Correlation Coefficient를 이용해 평가되었다. 통 계적 유의성은 $p<0.05$ 로 설정하였다.

\section{결 과}

중고등학교 엘리트 사이클 선수들의 유산소성 능력은 Table 1에서 보여주고 있다. 모든 선수가 자발적 최대수준에서
운동을 멈추었으며, 모든 선수가 마지막 단계에서 $\mathrm{VO}_{2}$ 의 고 원현상을 보인 것으로 평가되었다. 선수들의 $\mathrm{VO}_{2} \max$ 는 약 $10 \mathrm{ml} \cdot \mathrm{kg}^{-1} \cdot \mathrm{min}^{-1}$ 이상의 범위를 보였으며 운동지속시간은 12-17분대로 나타났다. 도달할 수 있는 최대운동강도는 452 $\mathrm{W}$ 였다. $\mathrm{VO}_{2} \max \left(\mathrm{ml} \cdot \mathrm{kg}^{-1} \cdot \mathrm{min}^{-1}\right.$ 로 환산된 수치)와 신체계측 변인(나이, 체중, 신체질량지수, 체지방율, 체표면적)과의 상관 관계는 존재하지 않는 것으로 나타났다 $(p>0.05)$.

Table 2에서는 운동강도의 변화에 따른 사이클 선수들의 심폐능력과 환기반응을 나타내고 있다. 대부분의 측정 및 환 산변인의 수치들은 운동강도가 증가하면서 지속적으로 상승 하였으나, 호흡시간 변인인 $\mathrm{Ti}, \mathrm{Te}, \mathrm{Tb}$ 는 감소하였고 $\mathrm{Ti} / \mathrm{Tb}$ 는 대체적으로 일정 수준에서 유지되었다. $\mathrm{V}_{\mathrm{E}} / \mathrm{VO}_{2}$ 와 $\mathrm{V}_{\mathrm{E}} / \mathrm{VCO}_{2}$ 는 운동강도가 증가하면서 약 $250-300 \mathrm{~W}$ 사이에서 교차 상승하였다.

안정시 폐기능 평가 변인과 수치는 Table 3에서 나타내고 있다. Table 4에서는 운동강도에 따른 신체계측변인과 호흡반 응 변인 간의 상관관계를 보여주고 있다. $250 \mathrm{~W}$ 이하에서 신 장, 체중, 신체질량지수, 체표면적이 $\mathrm{V}_{\mathrm{T}} / \mathrm{Ti}$ 그리고 $\mathrm{Ti} / \mathrm{Tb}$ 와 높은 상관관계를 나타냈다( $p<0.05)$.

Table 3. Young elite cyclists' pulmonary function

\begin{tabular}{lcc}
\hline & $\mathrm{M} \pm$ S.D. & Range $(\mathrm{n}=9)$ \\
\hline $\begin{array}{l}\text { functional vital capacity (FVC: liter) } \\
\text { forced expiratory volume in one }\end{array}$ & $5.58 \pm 0.65$ & $4.56-6.61$ \\
$\quad$ second ( $\mathrm{FEV}_{1}$ : liter) & & \\
$\mathrm{FEV}_{1} / \mathrm{FVC}(\%)$ & $83.9 \pm 6.6$ & $70.8-90.5$ \\
forced expiratory flow rate 25-75\% & $5.08 \pm 1.32$ & $3.37-7.02$ \\
$\quad \begin{array}{lll}\left(\mathrm{FEF}_{25-75 \%} \text { : liter) }\right. \\
\text { peak expiratory flow (PEF: liter) }\end{array}$ & $9.61 \pm 2.16$ & $7.07-12.86$ \\
\hline
\end{tabular}

Table 2. Cardiorespiratory and ventilatory responses during graded exercise testing in young elite cyclist

\begin{tabular}{|c|c|c|c|c|c|c|}
\hline Work load (W) & 100 & 200 & 250 & 300 & 350 & 400 \\
\hline HR (beat $\cdot \min ^{-1}$ ) & $132.8 \pm 8.9$ & $161.5 \pm 9.8$ & $174.2 \pm 8.6$ & $185.7 \pm 9.0$ & $193.9 \pm 9.3$ & $193.6 \pm 10.7$ \\
\hline RER & $0.89 \pm 0.05$ & $0.94 \pm 0.03$ & $0.98 \pm 0.05$ & $1.05 \pm 0.05$ & $1.11 \pm 0.05$ & $1.13 \pm 0.04$ \\
\hline $\mathrm{VO}_{2}\left(\mathrm{ml} \cdot \mathrm{kg}^{-1} \cdot \mathrm{min}^{-1}\right)$ & $27.1 \pm 3.4$ & $41.1 \pm 3.7$ & $47.5 \pm 4.5$ & $53.0 \pm 4.4$ & $57.1 \pm 4.0$ & $57.3 \pm 5.9$ \\
\hline $\mathrm{V}_{\mathrm{E}}\left(1 \cdot \mathrm{min}^{-1}\right)$ & $48.9 \pm 7.5$ & $74.4 \pm 7.9$ & $90.9 \pm 10.5$ & $116.2 \pm 11.8$ & $147.5 \pm 11.5$ & $179.9 \pm 9.2$ \\
\hline $\mathrm{VO}_{2}\left(1 \cdot \min ^{-1}\right)$ & $1.88 \pm 0.22$ & $2.84 \pm 0.21$ & $3.29 \pm 0.22$ & $3.67 \pm 0.24$ & $4.05 \pm 0.33$ & $4.55 \pm 0.15$ \\
\hline $\mathrm{VCO}_{2}\left(1 \cdot \mathrm{min}^{-1}\right)$ & $1.66 \pm 0.23$ & $2.67 \pm 0.19$ & $3.22 \pm 0.17$ & $3.85 \pm 0.20$ & $4.49 \pm 0.23$ & $5.13 \pm 0.28$ \\
\hline $\mathrm{V}_{\mathrm{E}} / \mathrm{VO}_{2}$ & $25.6 \pm 4.0$ & $25.6 \pm 1.9$ & $27.2 \pm 3.5$ & $31.1 \pm 3.5$ & $35.9 \pm 3.3$ & $38.8 \pm 1.2$ \\
\hline $\mathrm{V}_{\mathrm{E}} / \mathrm{VCO}_{2}$ & $29.0 \pm 5.1$ & $27.2 \pm 2.1$ & $27.7 \pm 2.9$ & $29.6 \pm 3.3$ & $32.2 \pm 2.6$ & $34.4 \pm 0.1$ \\
\hline RR (breath $\cdot \min ^{-1}$ ) & $26.3 \pm 7.0$ & $33.8 \pm 6.3$ & $38.9 \pm 7.4$ & $47.5 \pm 8.0$ & $56.8 \pm 5.7$ & $66.7 \pm 2.3$ \\
\hline $\mathrm{V}_{\mathrm{T}}$ (liter) & $1.96 \pm 0.43$ & $2.26 \pm 0.38$ & $2.40 \pm 0.40$ & $2.48 \pm 0.26$ & $2.61 \pm 0.16$ & $2.7 \pm 0.15$ \\
\hline $\mathrm{Ti}(\mathrm{sec})$ & $1.16 \pm 0.48$ & $0.88 \pm 0.19$ & $0.78 \pm 0.18$ & $0.64 \pm 0.11$ & $0.53 \pm 0.05$ & $0.43 \pm 0.01$ \\
\hline $\mathrm{Te}(\mathrm{sec})$ & $1.31 \pm 0.29$ & $0.96 \pm 0.17$ & $0.83 \pm 0.18$ & $0.66 \pm 0.11$ & $0.54 \pm 0.06$ & $0.47 \pm 0.02$ \\
\hline $\mathrm{Tb}(\mathrm{sec})$ & $2.47 \pm 0.73$ & $1.84 \pm 0.34$ & $1.61 \pm 0.36$ & $1.3 \pm 0.21$ & $1.07 \pm 0.1$ & $0.9 \pm 0.03$ \\
\hline $\mathrm{V}_{\mathrm{T}} / \mathrm{Ti}\left(\right.$ liter $\left.\cdot \mathrm{sec}^{-1}\right)$ & $1.79 \pm 0.38$ & $2.61 \pm 0.36$ & $3.14 \pm 0.41$ & $3.93 \pm 0.47$ & $4.94 \pm 0.40$ & $6.24 \pm 0.41$ \\
\hline $\mathrm{Ti} / \mathrm{Tb}$ & $0.46 \pm 0.05$ & $0.48 \pm 0.03$ & $0.48 \pm 0.02$ & $0.49 \pm 0.02$ & $0.5 \pm 0.02$ & $0.48 \pm 0.01$ \\
\hline
\end{tabular}

For legends, see text 
Table 4. Pearson Correlation Coefficient between Anthropometric and Breathing Parameters in Each Work Load

\begin{tabular}{ccccccccc}
\hline $\begin{array}{c}\text { Intensity } \\
(\mathrm{W})\end{array}$ & & $\mathrm{RR}$ & $\mathrm{V}_{\mathrm{T}}$ & $\mathrm{Ti}$ & $\mathrm{Te}$ & $\mathrm{Tb}$ & $\mathrm{V} \mathrm{T} / \mathrm{Ti}$ & $\mathrm{Ti} / \mathrm{Tb}$ \\
\hline & $\mathrm{Ht}$ & -0.119 & 0.461 & -0.017 & 0.138 & 0.044 & $0.576^{*}$ & -0.220 \\
100 & $\mathrm{Wt}$ & 0.049 & 0.310 & -0.211 & -0.077 & -0.168 & $0.716^{*}$ & -0.311 \\
$(\mathrm{n}=12)$ & $\mathrm{BMI}$ & 0.128 & 0.195 & -0.284 & -0.185 & -0.259 & $0.696^{*}$ & -0.312 \\
& $\mathrm{BSA}$ & 0.000 & 0.363 & -0.161 & -0.016 & -0.112 & $0.695^{*}$ & -0.294 \\
\hline & $\mathrm{Ht}$ & -0.407 & $0.701^{*}$ & 0.179 & 0.493 & 0.343 & 0.486 & -0.379 \\
200 & $\mathrm{Wt}$ & -0.142 & 0.485 & -0.097 & 0.281 & 0.084 & $0.669^{*}$ & $-0.582^{*}$ \\
$(\mathrm{n}=12)$ & $\mathrm{BMI}$ & 0.019 & 0.315 & -0.239 & 0.137 & -0.066 & $0.696^{*}$ & $-0.636^{*}$ \\
& $\mathrm{BSA}$ & -0.218 & 0.560 & -0.024 & 0.346 & 0.157 & $0.640^{*}$ & -0.541 \\
\hline & $\mathrm{Ht}$ & -0.234 & 0.459 & 0.022 & 0.149 & 0.087 & 0.388 & -0.330 \\
250 & $\mathrm{Wt}$ & -0.075 & 0.397 & -0.153 & 0.049 & -0.052 & $0.604^{*}$ & $-0.602^{*}$ \\
$(\mathrm{n}=12)$ & $\mathrm{BMI}$ & 0.025 & 0.324 & -0.239 & -0.011 & -0.125 & $0.673^{*}$ & $-0.704^{*}$ \\
& $\mathrm{BSA}$ & -0.118 & 0.423 & -0.113 & 0.075 & -0.018 & 0.565 & -0.546 \\
\hline & $\mathrm{Ht}$ & -0.111 & 0.281 & -0.027 & 0.020 & -0.004 & 0.216 & -0.137 \\
300 & $\mathrm{Wt}$ & 0.024 & 0.149 & -0.220 & -0.086 & -0.160 & 0.380 & -0.322 \\
$(\mathrm{n}=12)$ & $\mathrm{BMI}$ & 0.095 & 0.078 & -0.304 & -0.134 & -0.229 & 0.448 & -0.393 \\
& $\mathrm{BSA}$ & -0.012 & 0.192 & -0.177 & -0.059 & -0.124 & 0.353 & -0.288 \\
\hline & $\mathrm{Ht}$ & -0.025 & 0.529 & 0.029 & 0.060 & 0.049 & 0.351 & -0.029 \\
350 & $\mathrm{Wt}$ & 0.013 & 0.574 & -0.087 & 0.105 & 0.017 & 0.521 & -0.271 \\
$(\mathrm{n}=10)$ & $\mathrm{BMI}$ & 0.049 & 0.545 & -0.156 & 0.102 & -0.019 & 0.582 & -0.367 \\
& $\mathrm{BSA}$ & 0.009 & 0.577 & -0.068 & 0.095 & 0.020 & 0.501 & -0.224 \\
\hline
\end{tabular}

Ht: height, Wt: weight, BMI: body mass index, BSA: body surface area.

* significantly different $(p<0.05)$.

\section{고 찰}

\section{유산소성 능력 평가}

국내 중고등학교 엘리트 사이클 선수의 유산소성 능력을 체계적으로 측정하여 보고한 연구는 현재 거의 전무한 실정이 다[17]. 본 연구에서는 사이클 선수에게 적용 가능한 신뢰성 있는 프로토콜을 이용하여 측정하였지만 사실 이 프로토콜은 성숙한 엘리트 선수들을 대상으로 실시하여 검증된 프로토콜 에 불과하다. 이로 인해 어린 선수들의 유산소능력과 호흡반 응을 평가하기에 적합하지 않는 프로토콜일 수 있겠으며 이는 본 연구의 한계일 수 있다. 그러나 비록 성인에 적합한 방식일 지라도 기존의 선행연구의 결과들과의 비교는 가능할 것으로 여겨진다. 또한 아직 어린 사이클 선수들을 위해 평가되고 검 증된 널리 통용되는 점진부하 운동 프로토콜이 존재하지 않고 있으며, 따라서 성인에게 적용되는 방법을 선택하게 되었다. 특히 기존방식의 측정에 의해 평가된 어린 선수의 최대유산소 능력은 선수들의 훈련상태와 효과를 관찰하는데 중요한 자료 로 사용될 수 있지만 선수의 재능을 예측하거나 미래의 성공 을 예단하는 기준은 아닌 것으로 제안되고 있다[23]. 따라서 본 연구에서 선택한 방법이 선수들에 대해 절대적인 평가를 가능하게 한다기 보다는 호흡반응의 양상을 평가하기에 적합 할 수 있을 것으로 판단되었다.

본 연구에서 어린 선수들의 최대유산소능력은 유사한 검사
방법을 사용하여 얻은 성인의 수치들에 비해 낮게 나타났다. 국제적 수준의 엘리트 선수들의 $\mathrm{VO}_{2} \max$ 는 약 70-80 $\mathrm{ml} \cdot \mathrm{kg}^{-1} \cdot \mathrm{min}^{-1}$ 정도인 것으로 제시되고 있으며 $[18,20]$, 엘리트 선수의 훈련전과 후에도 각각 약 69 와 $78 \mathrm{ml} \cdot \mathrm{kg}^{-1} \cdot \mathrm{min}^{-1}$ 의 수 치를 보였다[12]. 10 명의 국내 남자 국가대표 선수들의 $\mathrm{VO}_{2} \mathrm{max}$ 는 약 $75 \pm 3 \mathrm{ml} \cdot \mathrm{kg}^{-1} \cdot \mathrm{min}^{-1}$ (범위 70-79)로 보고되고 있 다[28]. 성인 엘리트 선수를 대상으로 측정한 이 수치들은 본 연구의 대상자들에 비해 약 $10 \mathrm{ml} \cdot \mathrm{kg}^{-1} \cdot \mathrm{min}^{-1}$ 이상 높은 것으로 나타나고 있다.

김기진 등[17]에 의하면, 페달링 속도를 $50 \mathrm{rpm}$ 으로 고정하 고 2분 간격으로 $0.5 \mathrm{kp}$ 씩 증가시킨 실험에서, 두 명의 중학교 사이클 선수들로부터 약 $60 \mathrm{ml} \cdot \mathrm{kg}^{-1} \cdot \mathrm{min}^{-1}$ 의 $\mathrm{VO}_{2} \max$ 가 나타 났음을 보고하고 있다. 비록 본 연구에서 사용한 방법과는 다 른 평가방식을 택했지만 본 연구결과와 유사한 수치를 보여주 고 있다. 또한 본 연구의 어린 선수들의 최종 운동강도는 성인 선수들에 비해 약 40-80 W 낮은 것으로 나타나고 있다[18]. 운동을 지속한 시간을 보자면 성인의 지구력 시간보다 3-4분 정도 짧았음을 볼 수 있으며 이는 연령에 의존된 근지구력이 상대적으로 낮았음을 시사하고 있다.

어린 선수의 산소섭취량은 발육 정도에 따라 영향을 받는 것으로 제시되고 있으며[29], 특히 체중에 영향을 받는 것으로 이해되고 있다[1,5]. 즉 나이가 성인으로 이동할수록 그리고 체 중이 증가할수록 산소섭취량이 증가할 것으로 이해하고 있는 것이다. 그러나 본 연구에서 $\mathrm{VO}_{2} \max$ 나이 및 본 연구에서 신체 
특성 변인으로 선정한 체중, 신체질량지수, 체지방율, 체표면적 과 아무런 상관관계를 나타내지 않았다. 아마도 선행연구에서 는 많은 수의 훈련되지 않은 청소년을 대상으로 하였으며, 일부 자전거 대신 트레드밀을 사용하였다는 것에 그 차이가 기인했 을 것으로 생각된다. 다시 말해 본 연구에서 평가한 대상과 같은 엘리트 수준의 선수나 자전거 에르고미터를 이용한 평가였다 면 결과는 달라졌을 수 있다는 의미이다. 그러나 잘 훈련된 어린 선수들을 대상으로 자전거 에르고미터로 유산소능력을 평가했 을 때 체격요인이 영향을 미치지 않는다는 것은 추가적으로 체계적 연구방법을 동원하여 연구되어야 할 문제이다. 최소한 본 연구의 결과는 중고교 엘리트 사이클 선수의 $\mathrm{VO}_{2} \max$ 가 체격요인이나 연령으로 예견될 수 없음을 제안하고 있다. 그 리고 이는 성인과 어린 선수의 유산소능력을 평가할 때 서로 다른 방식으로 해석되어야 함을 제안하고 있는 것이다.

본 연구의 대상자들은 성인 엘리트 선수와 유사하거나 약간 낮은 환기량을 보였다. 엘리트 선수를 이용한 선행연구에서는 최대운동시 약 180-190 1의 환기량을 보고하고 있다[8,18]. 이 수준의 환기량은 고도로 훈련된 선수들에게서 나타나는 수준 이며, 이러한 수준의 환기량은 호흡저항을 낮게 유지해야만 가능한 호흡임을 표현한다[3]. 환기량과 산소섭취량을 연관 지 으면 본 연구의 어린 선수들은 성인들에 비해 산소호흡당량이 약간 높은 것으로 평가된다. 성인에 비해 높은 산소호흡당량 이 단지 훈련의 결과에 의한 것인지 아니면 중추신경에 의한 호흡조절이 성인과 다른 양상을 보이는 것인지는 명확하지 않다. 만약 본 연구에서의 폐기능 평가 변인의 결과를 인용한 다면 성인 선수들의 폐 기능과 크게 다르지 않으며 따라서 후자의 경우가 설득력 있는 것으로 보인다. 또한 어린 선수와 성인 선수의 또 한가지의 가능한 차이점은 바로 산소호흡당량 으로 평가될 수도 있음을 제안하고 있으며, 이 변인이 성인으 로 성장하면서 차차 낮아질 수 있음을 암시한다.

\section{폐환기 반응}

본 연구는 중고등학교 엘리트 사이클 선수들을 대상으로 점증부하운동 시 호흡 및 환기반응을 보고한 첫 연구로 사료 된다. 성인들을 대상으로 분석한 결과에 의하면 체중이나 신 장과 같은 체격 또는 신체계측변인이 운동 중 호흡반응 변인 $\left(\mathrm{V}_{\mathrm{T}}, \mathrm{RR}, \mathrm{Ti}, \mathrm{Te}\right.$ 등)에 영향을 미치는 것으로 보고되고 있다 [2,11]. 본 연구에서는 체중과 신장이 호흡반응 변인, 특히 시간 관련 변인 $\left(\mathrm{V}_{\mathrm{T}} / \mathrm{Ti}\right.$ 와 $\left.\mathrm{Ti} / \mathrm{Tb}\right)$ 과 상관관계가 있는 것으로 나타났 다. 그러나 이 반응이 약 $250 \mathrm{~W}$ 이하의 중저강도에서만 명확하 게 나타났으며, 신장보다는 체중과 더 연관성을 보였다. 즉 체중이 더 나가는 선수일수 약 $\mathrm{V}_{\mathrm{T}} / \mathrm{Ti}$ 가 더 컸으며, 반대로 $\mathrm{Ti} / \mathrm{Tb}$ 는 낮게 나타났다. 전자의 경우 체중이 많이 나갈수록 들이 쉬는 호흡에 소요되는 시간대비 일회호흡량이 많았음을 지적하고 있으며, 후자의 경우 체중이 많이 나가는 선수가 덜 나가는 선수에 비해 들이쉬는데 소요되는 시간이 더 짧았음을
암시한다. 중등강도 이하에서만 이러한 반응이 나타난 이유는 명확하지 않으며 이러한 현상이 훈련에 의한 결과도 아닌 것 으로 보인다[18]. 이 반응과 관찰은 추가적인 연구를 요구하며 어린 선수들의 고유의 호흡반응에 기인하는 것으로 여겨진다.

더 많이 훈련된 선수의 경우 들숨보다 날숨에 더 많은 시간 을 할애하며 이는 운동 강도가 강해질수록 더욱 명확하게 나 타나는 것으로 보고되었다[18]. 그러나 사이클 선수를 이용한 다른 연구에서는 운동강도가 강해지면서 호흡율이 상승하며 이는 들숨시간보다 날숨시간을 더 많이 감소시킴으로써 가능 하다고 제안되기도 하였다[9]. 본 연구에서는, 통계적으로 유 의하지 않았지만, 들숨에 할애하는 시간이 날숨에 할애하는 시간보다 적은 경향을 보였으며 운동의 강도와 무관하였다. 그리고 운동강도가 강해지면서 지속적으로 두 변인 모두 감소 하는 것으로 관찰되었다. 이처럼 선행연구들이 상반된 결과를 보고하고 있으며, 본 연구에서도 명확한 차이가 존재하지 않 는 것은 아마도 평가 시 선수들의 자세와 연관된 기계적 영향 이 작용하였을 것이다[18]. 즉 선수의 자전거 위에서 구부린 자세가 복부내장을 압박하고 동시에 날숨을 관장하는 근육이 다른 자세와 다른 수축양상을 보였을 것으로 추정하는 것이다.

일회호흡량과 흡기시간의 비율은 흡기 중추 작용(central inspiratory drive)을 간접적으로 평가하는 방식으로 제안되고 있다[24]. 이 지표는 고도로 훈련된 선수의 경우에도 훈련에 의해 변화되는 것으로 보이지 않으며[18], 운동의 강도가 강해 지면 그 수치는 점차적으로 증가한다. 성인 엘리트 선수를 대 상으로 평가한 선행연구에서는 $200,300,350 \mathrm{~W}$ 에서 각각 약 $2,2.8,31 / \mathrm{sec}$ 을 보이고 있으며, 이는 본 연구에서 같은 운동강 도의 수치에 비해 상당히 낮은 수치로 보인다. 그럼에도 본 연구에서의 최대치가 $6 \mathrm{l} / \mathrm{sec}$ 이상을 상회하고 있고 이는 성인 사이클 선수들의 최대치와 유사한 것으로 보인다. 이러한 결 과는 나이와 무관하게 흡기율이 선수들의 운동지속능력과 관 련되어 진행되는 것임을 암시한다. 즉 성인에 비해 각 단계의 운동강도에서 높은 수치의 흡기율을 나타내는 것은 그만큼 높은 수준의 흡기중추 작용을 요구하는 것이며, 따라서 어린 선수의 경우 상대적으로 낮은 강도에서 호흡 스트레스가 증가 하는 것을 의미한다. 또 다른 해석으로 흡기율이 높다는 것은 그 만큼 호흡에 사용하는 대사비용(metabolic cost)이 증가한 다는 것이며 이는 운동지속능력을 제한하는 요인으로 작용한 다는 의미일 것이다.

본 연구에서 흡기의무사이클은 운동의 강도와 무관하게 약 0.5 이하에서 일정하게 유지되었다. 이는 성인 사이클 선수와 유사한 수준인 것으로 평가된다[9,18]. 그리고 어린 선수의 경 우에도 호흡근육의 기계적 작동이 효율적으로 진행되는 것을 암시한다[18]. 최소한 성인과 비교하여 설명되어진 다른 평가 변인들과는 다르게 흡기의무사이클은 나이와 상관없이 잘 훈 련된 선수들에게서 공통적으로 일정한 수준을 보이는 것이 타당한 반응으로 해석되어진다. 
폐기능

선수의 폐기능은 지구성 운동능력에 영향을 주는 한 요인이 다. 한국 남자 국가대표 사이클 선수들을 대상으로 조사한 결 과는 $\mathrm{FVC}, \mathrm{FEV}_{1}, \mathrm{FEV}_{1} / \mathrm{FVC}$ 가 각각 $4.98 \pm 0.431,4.51 \pm 0.50$ liter, $88.8 \pm 8.1 \%$ 로 보고되고 있다[28]. 본 연구에서 어린 선수 들의 $\mathrm{FVC}$ 가 선행연구의 성인 선수들에 비해 오히려 높은 것 으로 나타났다. 아마도 측정 당시 최대한으로 많은 양의 공기 를 불어내라는 격려에 의한 차이일 수 있을 것이다. 그러나 측정오차를 감안하더라도 어린 사이클 선수의 신장이 이미 성인의 신장과 유사한 수준에 이르렀으며, 이는 $\mathrm{FVC}$ 를 결정 짓는 요인으로 작용하였을 것이다. 또는 신장과 체중에 비해 어린선수들의 폐환기 저항이 성인의 그것들에 비해 더 낮음에 기인할 수도 있을 것이다. 이러한 해석이 가능한 이유는 비록 낮은 운동강도에서 운동을 멈추었음에도 어린 선수들의 환기 량이 성인의 환기량에 비해 약간 낮거나 거의 유사한 수준을 보였다는 것을 상기하면 쉽게 수긍이 간다. 즉 낮은 강도에서 운동을 중단하였음에도 불구하고 마지막에 유사한 환기량을 보였다는 것을 운동강도에 대비하여 더 많은 환기량을 보였다 는 의미이기 때문이다. 즉 어린선수들의 환기저항이 성인의 그것에 비해 낮을 수 있다는 것이다.

선행연구에 의하면 보통 사람의 경우 운동 시 자신의 일회 호흡량을 폐활량의 $75 \%$ 까지 상승시킬 수 있으며, 호흡의 기계 적 제한(mechanical limitation)이 존재하지 않는다면 호흡율 은 분단 45 회까지 가능하다고 제시하고 있다[26]. 본 연구에서 어린 선수들은 최대운동 시 호흡율을 최대 60회 이상으로 상 승시켰으며 일회호흡량은 폐활량의 약 $48 \%$ 를 사용하였다. 성 인 사이클 선수의 경우 이보다 약간 높은 53-60\%를 사용하였 다고 보고된다[18]. 이는 어린 선수의 경우에도 사이클 운동 시 기계적 제한이 존재하지 않는다는 것을 의미한다. 아마도 점진부하로 최대운동에 이른 경우에 관찰된 환기량과 어린 선수들의 폐활량과 무관하지 않을 것이다.

결과적으로, 선행연구에서 보고된 결과들과 비교하여 중고 교 엘리트 사이클 선수들의 최대유산소능력은 성인에 비해 낮은 것으로 보인다. 본 연구의 선수들이 성인의 환기량과 유 사함에도 $\mathrm{VO}_{2} \mathrm{max}$ 가 낮은 것은 성인과 다른 호흡조절 양상을 가진 것으로 추정하게 한다. 신체계측 변인은 $\mathrm{VO}_{2} \max$ 와 상관 성이 존재하지 않아 성인의 연구들과 다른 결과를 보였다. 호 흡반응의 시간변인은 운동강도 $250 \mathrm{~W}$ 이하에서만 체격과 연 관성을 가지는 것으로 보인다. 흡기율은 어린 선수들의 운동 지속시간과 연관 있어 보이지만, 흡기의무사이클은 성인과 유 사한 것으로 보인다.

\section{감사의 글}

본 연구는 체육인재육성재단의 지역강세인재양성사업의 일환으로 추진된 스포츠과학 기반 우수 사이클 인재 양성 시 스템 구축 과제로 지원되었음.

\section{Refereces}

1. Armstrong, N., J. Williams, J. Balding, P. Gentle, and B. Kirby. 1991. The peak oxygen uptake of British children with reference to age, sex and sexual maturity. European Journal of Applied Physiology and Occupational Physiology 62, 369-375.

2. Asmussen, E., N. H. Secher, and E. A. Andersen. 1981. Heart rate and ventilatory frequency as dimension-dependent variables. European Journal of Applied Physiology and Occupational Physiology 46, 379-386.

3. Clark, J. M., F. C. Hagerman, and R. Gelfand. 1983. Breathing patterns during submaximal and maximal exercise in elite oarsmen. Journal of Applied Physiology 55, 440-446.

4. Coyle, E. F. 1999. Physiologicl determinants of endurance exercise performance. Journal of Science and Medicine in Sport 2, 181-189.

5. Davies, C. T. M., C. Barnes, and S. Godfrey. 1972. Body composition and maximal exercise performance in children. Human Biology 44, 195-214.

6. DuBois, D. and E. F. DuBois. 1916. A formula to estimate the appropriate surface area if height and weight be known. Archives Internal Medicine 17, 863-871.

7. Faria, E. W., D. L., Parker, and I. E. Faria. 2005. The science of cycling: physiology and training - part 1. Sports Medicine 35, 285-312.

8. Faria, I. E., E. W. Faria, S. Roberts, and D. Yoshimura. 1989. Comparison of physical and physiological characteristics in elite young and mature cyclists. Research Quarterly for Exercise and Sport 60, 388-395.

9. Folinsbee, L. J., E. S. Wallace, J. F. Bedi, and S. M. Horvath. 1983. Exercise respiratory pattern in elite cyclists and sedentary subjects. Medicine and Science in Sports and Exercise 15, 503-509.

10. Gallagher, C. G., E. Brown, and M. Younes. 1987. Breathing pattern during maximal exercise and during submaximal exercise with hypercapnia. Journal of Applied Physiology 63, 238-244.

11. Gaultier, C., L. Perret, M. Boule, A. Buvry, and F. Girard. 1981. Occlusion pressure and breathing pattern in healthy children. Respiratory Physiology 46, 71-80.

12. Hoogeveen, A. R. 2000. The effect of endurance training on the ventilatory response to exercise in elite cyclists. European Journal of Applied Physiology 82, 45-51.

13. Impellizzeri, F. M., E. Rampinini, A. Sassi, P. Mognoni, and S. M. Marcora. 2005. Physiological correlates to off-road cycling performance. Journal of Sports Science 23, 41-47.

14. Kim, J. H. and E. K. Kim. 2009. The effects of periodization of strength training on athletic performance related to cycling speed in elite middle and long distance cyclists. Korean Journal of Physical Education 48, 375-388.

15. Kim, J. H. and S. W. Yoon. 2005. The effect of road cycling training combined with strength and sprint interval training on short distance cycling-related performance. Korean Journal of Physical Education 48, 479-488. 
16. Kim, J. H. 2008. Construction of physical fitness evaluation norm and training program for racing cyclists. Korea Institute of Sport Science. Research Report 2008-2025.

17. Kim, K. J., H. K. Ahn, D. S. Jung, S. W. Yoon, J. H. Kim, T. Y. Jung, Y. W. Lee, and C. S. Kim. 1993. Physiological analysis for the determination of detailed event in young cyclists. Korean Journal of Sports Medicine 11, 14-31.

18. Lucía, A., A. Carvajal, F. J. Calderón, A. Alfonso, and J. L. Chicharro. 1999. Breathing pattern in highly competitive cyclists during incremental exercise. European Journal of Applied Physiology and Occupational Physiology 79, 512-521.

19. Lucía, A., J. Hoyos, and J. L. Chicharro. 2001a. Physiology of professional road racing. Sports Medicine 31, 325-337.

20. Lucía, A., J. Hoyos, and J. L. Chicharro. 2001b. Preferred pedalling cadence in professional cycling. Medicine and Science in Sports and Exercise 33, 1361-1366.

21. McParland, C., B. Krishnan, J. Lobo, and C. G. Gallagher. 1992. Effect of physical training on breathing pattern during progressive exercise. Respiratory Physiology 90, 311-323.

22. McParland, C., J. Mink, and C. G. Gallagher. 1991. Respiratory adaptations to dead space loading during maximal incremental exercise. Journal of Applied Physiology 70, 55-62.

23. Menaspà, P., A. Sassi, and F. M. Impellizzeri. 2009. Aerobic fitness variables do not predict the professional career of young cyclists. Medicine and Science in Sports and Exercise. [Epub ahead of print]

24. Miilic-Emili, J. and M. M. Grunstein. 1976. Drive and timing components of ventilation. Chest 70, 131-133.
25. Mora-Rodriguez, R. and R. Aguado-Jimenez. 2006. Performance at high pedaling cadences in well-trained cyclists. Medicine and Science in Sports and Exercise 38, 953-957.

26. Otis, A. B. and A. R. Guyatt. 1968. The maximal frequency of breathing of man at various tidal volumes. Respiratory Physiology 5, 118-129.

27. Padilla, A., I. Mujika, G. Cuesta, and J. J Goiriena. 1999. Level ground and uphill cycling ability in professional road cycling. Medicine and Science in Sports and Exercise 31, 878-885.

28. Park, D. H. 2005. Basic, specific and selected fitness measurements and evaluation during the first half period of national team cyclists. Technical Report on Field Application of Sports Science (I), Korea Institute of Sport Science.

29. Rutenfranz, J., K. Lange Andersen, V. Seliger, J. Ilmarinen, F. Klimmer, H. Kylian, M. Rutenfranz, and M. Ruppel. 1982. Maximal aerobic power affected by maturation and body growth during childhood and adolescence. European Journal of Pediatrics 139, 106-112.

30. Tanaka, H., D. R. Bassettr, T. S. Swensen, and R. M. Sampedro. 1993. Aerobic and anaerobic power characteristics of competitive cyclists in the United States Cycling Federation. International Journal of Sports Medicine 14, 334-338.

31. Yamaji, K. and M. Miyashita. 1978. Differences in cardio-respiratory responses to exhaustive exercise between athletes and non-athletes. European Journal of Applied Physiology and Occupational Physiology.38, 233-238.

\section{초록 : 점진부하 운동에서 중고교 엘리트 사이클 선수들의 유산소능력과 폐환기 반응 \\ 이대택** 배윤정 \\ (국민대학교 김창규운동생리학실험실)}

국내 중고교 엘리트 사이클 선수를 대상으로 점진부하 운동 시 유산소반응과 폐환기 반응을 분석하는데 목적 을 두었다. 남자 사이클 선수 $(17 \pm 1$ 세, $175 \pm 5 \mathrm{~cm}, 70 \pm 9 \mathrm{~kg}) 12$ 명이 신체계측, 점진부하 운동 검사, 폐기능 검사에 참여하였다. 사이클 에르고미터를 이용한 점진부하 운동 중 이들의 최대산소섭취량( $\mathrm{VO}_{2} \mathrm{max}$ 과 최대파워 (Wmax), 환기량, 산소 및 이산화탄소호흡당량 $\left(\mathrm{V}_{\mathrm{E}} / \mathrm{VO}_{2}, \mathrm{~V}_{\mathrm{E}} / \mathrm{VCO}_{2}\right)$, 호흡율, 일회호흡량 등이 측정되었다. 호흡반 응의 시간변인으로 흡기시간(Ti), 호기시간(Te), 일회호흡시간 $(\mathrm{Tb})$, 흡기의무사이클 $(\mathrm{Ti} / \mathrm{Tb})$, 흡기율 $\left(\mathrm{V}_{\mathrm{T}} / \mathrm{Ti}\right)$ 이 분석 되었다. 폐기능으로는 폐활량, 일초호기량, 일초율, 최대호기량 등이 측정되었다. 선수들은 최대운동시 $57.5 \pm 3.9$ $\mathrm{ml} \cdot \mathrm{kg}^{-1} \cdot \mathrm{min}^{-1}$ 의 $\mathrm{VO}_{2} \max , 194.1 \pm 8.6$ beat $\mathrm{min}^{-1}$ 의 최대심박수를 보였으며, $\mathrm{Wmax}$ 는 평균 $452 \mathrm{~W}$ 에 도달하였다. $\mathrm{VO}_{2} \max$ 은 신체계측 변인들과 상관관계를 보이지 않았다. 대부분의 환기반응은 운동강도가 점차적으로 증가하 면서 동반 증가하였다. 운동강도의 증가와 함께 $\mathrm{Ti}, \mathrm{Te}, \mathrm{Tb}$ 는 감소하였으며, $\mathrm{Ti} / \mathrm{Tb}$ 는 대략적으로 일정하게 유지되 었다. $250 \mathrm{~W}$ 이하에서 신장, 체중, 신체질량지수, 체표면적은 $\mathrm{V}_{\mathrm{T}} / \mathrm{Ti}$ 그리고 $\mathrm{Ti} / \mathrm{Tb}$ 와 높은 상관관계를 나타냈다 $(p \times 0.05)$. 결과적으로, 엘리트 사이클 선수들의 최대유산소능력은 성인에 비해 낮은 것으로 보이며, 이는 성인과 호흡조절 양상이 다른 것으로 추정된다. 신체계측 변인은 $\mathrm{VO}_{2} \max$ 와 상관성이 존재하지 않았다. 호흡반응의 시간 변인은 운동강도 $250 \mathrm{~W}$ 이하에서만 체격과 연관성을 가지는 것으로 보인다. 흡기율은 어린 선수들의 운동지속시 간과 연관 있어 보이지만, 흡기의무사이클은 성인과 유사한 것으로 보인다. 